\title{
PV Module Modeling and Maximum Power Point Tracking Based on Asymmetric Fuzzy Control
}

\author{
Hongjun $\mathrm{XiaO}^{1}$, Xianxiang $\mathrm{Li}^{1^{\star}}$ \& Jun $\mathrm{Wu}^{1}$, Zhongliang $\mathrm{LuO}^{2}$
}

1Mechanical and electric engineering college, Foshan University, Foshan, Guangdong, China

2Department of Electronic Science, Huizhou University, Huizhou, Guangdong, China

KEYWORD: PV; the single-diode model; MPPT; asymmetric fuzzy control (AFC)

\begin{abstract}
In this paper, a parameter estimation method for the single diode model of photovoltaic (PV) module is proposed, and the simulation model of PV module is established. Based on the analysis of the PV module output characteristics under different temperature and irradiance, the monotonic decreasing characteristics of the output power derivative with regard to the output voltage is obtained, and the slope of this function is completely different at both sides of the maximum power point (MPP). Finally, according to those features, the asymmetric fuzzy controller of PV module for maximum power point tracking (MPPT) is designed. The main advantage of the proposed MPPT, compared with MPPT based on symmetric fuzzy control (SFC), is faster, slightly higher efficiency and smaller oscillation.
\end{abstract}

\section{INSTRUCTION}

The sun radiates an enormous amount of power, out of which approximately is $1.8^{*} 10^{11} \mathrm{MW}$ intercepted by Earth. This is several thousand times the present energy consumption of the entire world [Sachin Jain, 2007]. At the same time, the solar energy is clean and renewable. So, the research about the utilization of energy is one of the most popular fields. The main utilization of energy includes light-heat conversion and photoelectric conversion in two ways, of which the photoelectric conversion is more commonly used. PV cell is an energy conversion device that transfers light energy into electrical energy. Single PV cell is the minimum unit which constitute PV module. The Current-Voltage ( $\mathrm{I} U$ ) characteristics curves of PV module are different and nonlinear under different irradiance and temperature. The MPP of the PV module changes accordingly. PV module has to work at MPP to improve its efficiency, therefore, MPPT is necessary for PV generation system.

\section{MODEL OF PV MODULE AND ITS OUTPUT CHARACTERISTICS}

\subsection{Parameters evaluations of PV Module}

The model of PV module contains the double-diode model and the single-diode model [Xiao Weidong, 2004]. It is more difficult to determine the 6 parameters in the double-diode model than the 5 parameters in the single-diode model, but the double-diode model does not improve accuracy significantly [Gao Xiankun, 2014]. Figure 1. is the equivalent circuit of single-diode model. The mathematical model is given by

$I=I_{p v}-I_{d o}\left(e^{\Lambda}-1\right)-\left(U+R_{s} I\right) / R_{p}$

Where $\Lambda=q\left(U+R_{s} I\right) / N_{s} A k T_{c}, U, I$ represents the thermal voltage and current of the equivalent circuit above respectively, $I_{d o}$ is the diode satura-tion current, $\mathbf{q}$ is the electron charge

(C) , $k$ is Boltzmann constant $\left(1: 38 £ 10^{i}{ }^{23} \mathrm{~J} / \mathrm{K}\right)$, and $A$ is the diode ideality factor, $R_{S}$ is the series resistance, $R_{p}$ is the shunt resistance. 


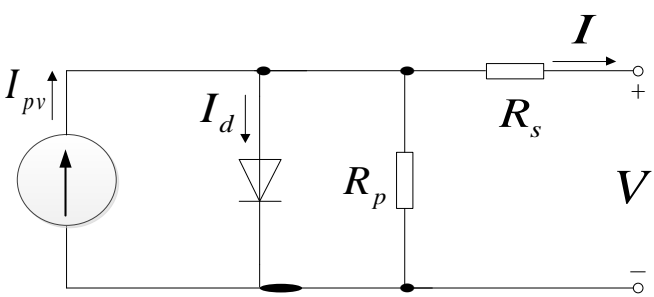

Figure 1. The equivalent circuit of PV module

The datasheet of PV module usually provide the product's data under standard test condition(STC, defined as irradiate of $1000 \mathrm{~W} / \mathrm{m} 2$ at AM 1.5 solar spectrum and cell temperature $25^{\circ} \mathrm{C}$ ), such as short circuit current $I_{s c, S T C}$, open circuit voltage $U_{o c, S T C}$, current $I_{m p p, S T C}$ and voltage $U_{m p p, S T C}$ at maximum power point, as well as number of cells in series $N_{s}$, temperature coefficients of current $k_{i}$, temperature coefficients of voltage $k_{u}$.

According to Eqn.(1), three equations can be obtained when the circuit is open, shorted and working at MPP. With any two equations, the five parameters in Eqn.(1) can be solved.

$\mathrm{R}$ Chenni [R Chenni, 2007] gives the relationship between the diode saturation currents under STC $\left(I_{d o, S T C}\right)$ and any temperature $\left(I_{d o, R}\right)$, that is,

$I_{d o, R}=I_{d o, S T C}\left(\frac{T_{c, R}}{T_{c, S T C}}\right)^{3} \exp \left(\frac{q \varepsilon_{G}}{k A} \Phi\right)$

where $\Phi=1 / T_{c, S T C}-1 / T_{c, R}, \varepsilon_{G}$ is bandgap energy.

Furthermore, Hermann [W Herrmann, 1996] introduced the relationship between the photo current under STC $\left(I_{p v, S T C}\right)$ and under any temperature and irradiance $\left(I_{p v, R}\right)$, that is,

$I_{p v, R}=I_{p v, S T C}\left[1+k_{i}\left(T_{c, R}-T_{c, S T C}\right)\right] \frac{S}{S_{S T C}}$

Under standard irradiance and any temperature, according to the datasheet, the current and voltage can be described as follow:

$I_{s c, R}=I_{s c, S T C}\left(1+\Delta T_{c} k_{i}\right)$

$U_{o c, R}=U_{o c, S T C}\left(1+\Delta T_{c} k_{u}\right)$

For simplicity, define $\Delta T_{c}=1_{\mathrm{K}}$, that is $T_{c, R}=299.15_{\mathrm{K}}$. With the above four equations, two equations can be obtained from Eqn.(1) when the circuit is open and shorted under $T_{c, R}=299.15_{\mathrm{K}}$ and standard irradiance.

From above, five independent equations are estab-lished, which makes the five parameters in Eqn.(1) solvable. Considering the nonlinear and implicit fea-ture of Eqn.(1), newton iteration method is applied.

\subsection{Model's output characteristics of the PV module}

In this paper, the simulation model about PANDA 48cell is established based on MATLAB/ Simulink. Figure 2. shows the output characteristics under standard temperature, that is the cell temperature is $25^{\circ} \mathrm{C}$, and the irradiance changing from $200 \mathrm{~W} / \mathrm{m} 2$ to $1000 \mathrm{~W} / \mathrm{m} 2$. Figure 3 . shows the output characteris-tics under standard irradiance, that is $1000 \mathrm{~W} / \mathrm{m} 2$, and the temperature changing from $20{ }^{\circ} \mathrm{C}$ to $100^{\circ} \mathrm{C}$. From the two figures, we can get that the output characteristics are nonlinear under different temperature and irradiance, and the MPP changing with the temperature and irradiance. 

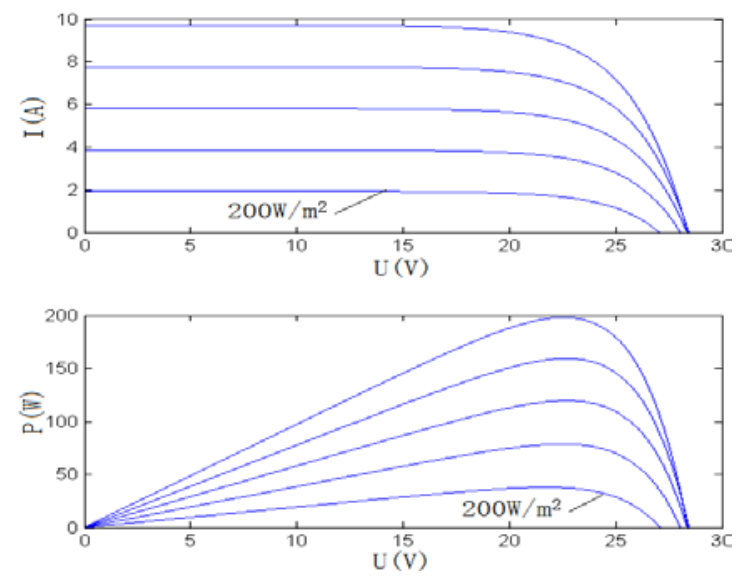

Figure 2. The output characteristics under standard temperature and different irradiance.
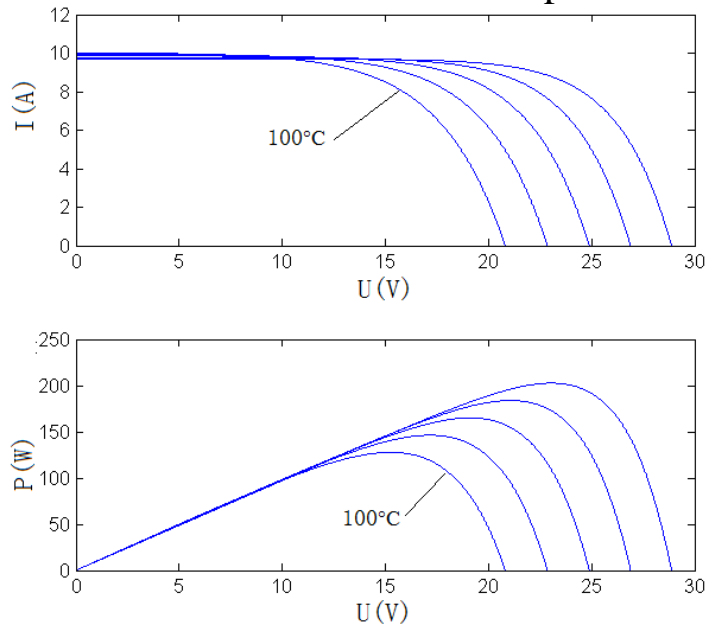

Figure 3. The output characteristics under standard irradiance and different temperature.

Furthermore, from the above two figures, $d P / d U$ is not symmetric about MPP. Substituting Eqn. (1) to $P=U I$, the derivative is given by

$\frac{d P}{d U}=I_{p v}-I_{d o} e^{\Lambda}\left(1+\frac{q U}{A k T_{c}}\right)-I_{d o}-\frac{2 U+R_{s} I}{R_{p}}$

Eqn.(6) shows that $d P / d U$ is a monotonic decre-asing function. Furthermore, Figure 4. presents the $P-U$ relationship and $d P / d U-U$ relationship under Tc $=20^{\circ} \mathrm{C}$ and $\mathrm{S}=800 \mathrm{~W} / \mathrm{m} 2$. When the output voltage is zero, $d P / d U$ achieves the maximum value, then falling slowly with the increase of the output voltage. At MPP, $d P / d U=0$, then $d P / d U$ become negative, and fall faster and faster.
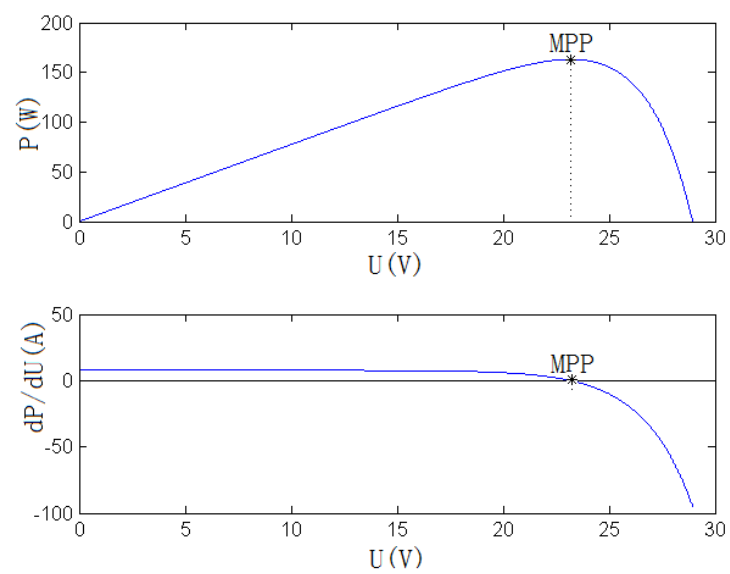

Figure 4. The $P-U$ and $d P / d U-U$ relationships of the PV module. 


\section{ASYMMETRIC FUZZY CONTROL OF THE MPPT SYSTEM}

As a intelligent control technology, fuzzy control shows wide application, nice robustness and independent of the mathematical model. Therefore, it is capable to control the photovoltaic power generation system which contains uncertainty, and difficult to develop accurate mathematical model [Chiu Chiansong, 2010].they do not require the knowledge of the exact model Among the structures of the fuzzy controller, double inputs and single output are the most commonly used. Generally, the error and its derivative, which can reflects the PD control effect, are picked to be the inputs. Define $e=\Delta P / \Delta U$, then $e=0$ means that the PV module works at MPP. As $d P / d U$ is monotonic decreasing and asymmetric at MPP's both sides, the oscillation of output power with symmetric fuzzy control is large [Zhang Chao, 2009]. Furthermore, the derivative of the error is also monotonic decreasing. With the increase of $U$, its absolute value increases exponentially. In this paper, according to the asymmetrical characteristic of the model, MPPT of PV module based on asymmetric fuzzy control is proposed. The control block diagram is shown in Figure 5. The output of fuzzy controller adjusts the duty cycle of boost circuit to make the PV module work at MPP.

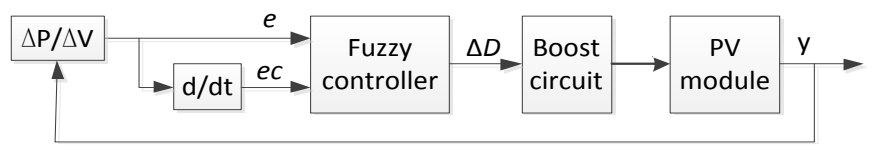

Figure 5. The control block diagram based on asymmetric fuzzy control

\section{ASYMMETRIC FUZZY CONTROL DESIGN}

\subsection{Determining of inputs, output and the fuzzy sets}

The error $e$ and its derivative $e c$ is given by

$e(k)=\frac{P(k)-P(k-1)}{U(k)-U(k-1)}$

$e c=e(k)-e(k-1)$

Actually, if the sampling period is small enough, the error e is the derivative of the power with respect to voltage, which is shown in Eqn.(6). When the error is zero, the corresponding output power is the maximum. By means of the quantification factor, the basic domain of e (ec) can be converted from $[-\mathrm{e}, \mathrm{e}]([-\mathrm{ec}, \mathrm{ec}])$ to $\mathrm{X}=\{-\mathrm{m},-\mathrm{m}+1, \ldots, 0, \ldots, \mathrm{m}-1, \mathrm{~m}\}$. Besides, by means of the scaling factor, the output of the fuzzy controller can be converted to the duty cycle of the MPPT circuit. Then, the domain of the inputs and output are defined as [-7,7] and [-1,1] separately, all of the fuzzy sets with regard to the inputs and output variables are defined as $\{\mathrm{NB}, \mathrm{NM}, \mathrm{NS}, \mathrm{ZE}, \mathrm{PS}$, PM, PB\} accordingly.

\subsection{Determining of the membership functions}

Considering the asymmetric characteristic of the output at MPP's both sides, the asymmetric triangle membership function is used for the output, and the symmetric triangle membership function is used for the inputs, which is shown in Figure 6. Furthermore, to improve the control precision and reduce the oscillation, greater slope of the membership function is used for smaller error zone.

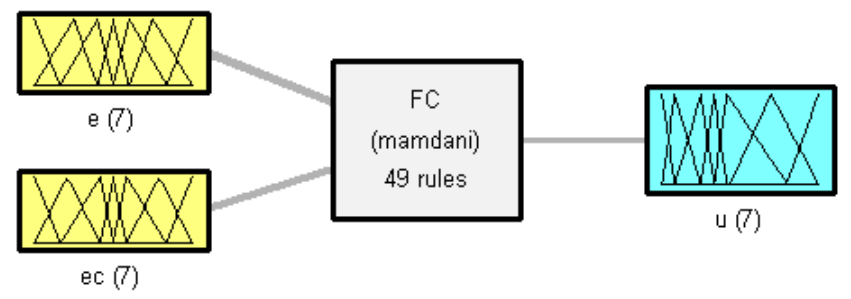

Figure 6. The block diagram of asymmetric fuzzy controller 


\subsection{Determining of the fuzzy control rules}

Note that $\mathrm{e}<0$ means that the PV module works at the right side of MPP, and e $>0$ means that the PV module works at the left side of MPP. Besides, $d P / d U$ is monotonic decreasing. ec $<0$ means the output voltage is increasing while ec $>0$ means the output voltage is decreasing. Therefore, the fuzzy control rules is established as Table 1. It can be seen that the control rules is asymmetric. For example, when e and ec are all PS, the output would be PB, as the PV module works at the left side of MPP, ec changes slowly. When e and ec are all NS, the output would be $\mathrm{NM}$, as the PV module works at the right side of MPP, ec changes fast.

Table 1. fuzzy control rules

\begin{tabular}{llllllll}
\hline & \multicolumn{7}{c}{$e$} \\
\cline { 2 - 7 } & PB & PM & PS & Z & NS & NM & NB \\
\hline PB & PB & PB & PB & PM & Z & NS & NM \\
PM & PB & PB & PB & PS & NS & NM & NM \\
PS & PB & PB & PB & PS & NM & NM & NM \\
$Z$ & PB & PB & PM & Z & NM & NM & NB \\
NS & PB & PM & PM & NS & NM & NB & NB \\
NM & PM & PM & PS & NS & NB & NB & NB \\
NB & PM & PS & $Z$ & NM & NB & NB & NB \\
\hline
\end{tabular}

\section{SIMULATION}

The simulation model is estimated based on Matlab /Simulink, which consist of the PANDA PV module, fuzzy controller and boost converter. The switching frequency of the power device is $1 \mathrm{~K}$. Under standard temperate, the irradiance begins at $600 \mathrm{~W} / \mathrm{m} 2$, and then changes to $400 \mathrm{~W} / \mathrm{m} 2$ at $100 \mathrm{~ms}, 800 \mathrm{~W} / \mathrm{m} 2$ at $200 \mathrm{~ms}$. Figure 7 . shows the results, and Table.2 presents the tracking time using SFC and AFC when the irradiance changes. Also, Table.2 shows that the tracking time of AFC is much sooner than that of SFC. Specifically, when the irradiance changes from 0 to $600 \mathrm{~W} / \mathrm{m} 2$, and from $400 \mathrm{~W} / \mathrm{m} 2$ to $800 \mathrm{~W} / \mathrm{m} 2$, the initial point is on the left side of MPP, the tracking speed of AFC is four times faster than that of SFC. However, when the irradiance changes from $600 \mathrm{~W} / \mathrm{m} 2$ to $400 \mathrm{~W} / \mathrm{m} 2$, the initial point is on the left side of MPP, the advantage of AFC is not very obvious. The reason is that, when the initial point is on the left of MPP, the error is large, the rate of change for the characteristic curve in this area is small, the output voltage is required to increase as soon as possible to speed up the tracking MPP. So the output of fuzzy controller is PB, as shown in Table 1. It can be seen from Figure 6., the value of $\mathrm{PB}$ is much greater than the absolute value of NB, which can increase the output voltage as soon as possible in this area. In contrast, SFC cannot make the voltage increase fast enough. Because when the output membership functions is symmetrical, the output absolute value of NB corresponding PB is large. It means to decrease the output voltage as soon as possible, when the current point is on the right of MPP. Obviously, it is unsuited because $d P / d U-U$ changes very fast in this area.

Table 2. Step response time with different methods

\begin{tabular}{lccc}
\hline & \multicolumn{3}{c}{ steady time (ms) } \\
\cline { 2 - 4 } & $0-600 \mathrm{~W} / \mathrm{m}^{2}$ & $600-400 \mathrm{~W} / \mathrm{m}^{2}$ & $400-800 \mathrm{~W} / \mathrm{m}^{2}$ \\
\hline SFC & 58 & 39 & 47 \\
AFC & 13 & 31 & 11 \\
\hline
\end{tabular}




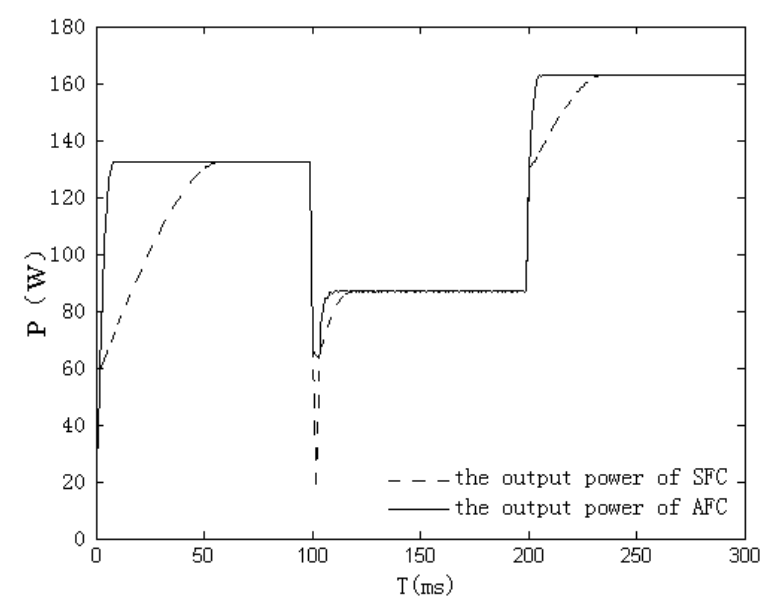

Figure 7. The tracking curve when the irradiance change.

Figure 8. shows the enlarged view of tracking curve when the irradiance is $400 \mathrm{~W} / \mathrm{m} 2$. Whether AFC or SFC, the error between output power and the output power of model is small, of which the error of AFC is smaller, less than $0.1 \%$. It also can be seen, the output power of AFC has smaller oscillation, which is about equal to $0.1 \%$.

\section{CONCLUSION}

In this paper, a parameter estimation method for the single diode model of PV module is proposed, and the simulation model of PV module is established. The simulation results demonstrate the PV module output characteristics are different and nonlinear under different temperature and irradiance, and the output power derivative with regard to the output voltage is monotonic decreasing. According to those features, the asymmetric fuzzy controller for MPPT is designed. The simulation results show that the proposed MPPT based on AFC track fast, and has small oscillation.

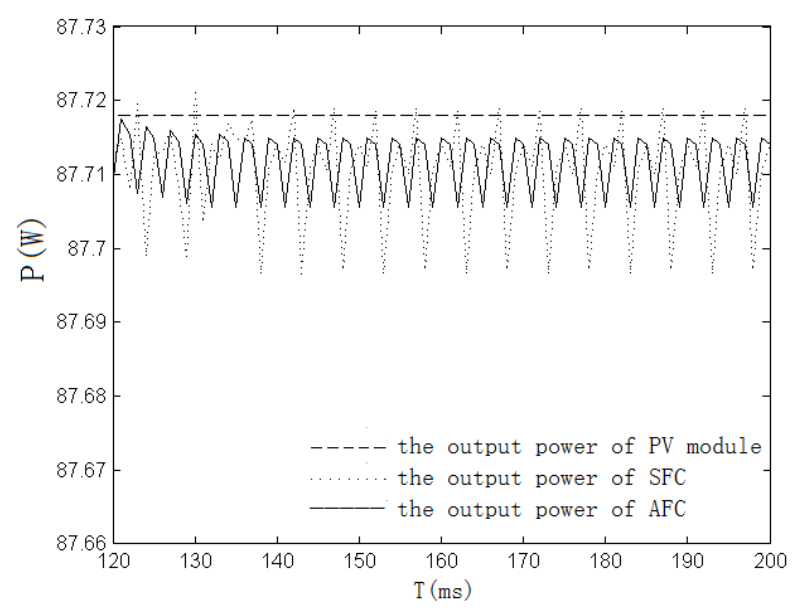

Figure 8. Enlarged view of the tracking curve when the irradiance is $400 \mathrm{~W} / \mathrm{m}^{2}$

\section{ACKNOWLEDGEMENTS}

This work was supported by the Science and Tech-nology Planning Project of Guangdong Province, China (2011B010100015) and the Special Fund Fo-shan Technology Development, China (2012AA100-651). The corresponding author is Xianxiang Li, of which Email address is lixx@fosu.edu.cn. Besides, many thanks should also be given to reviewers for this paper. 


\section{REFERENCES}

[1] Sachin Jain et al. 2007. New current control based MPPT technique for single stage grid connected PV systems. Energy conversion and management 48(2):625-644.

[2] Xiao Weidong et al. 2004. A novel modeling method for pho-tovoltaic cells. Power Electronics Specialists Conference 3:1950-1956.

[3] Gao Xiankun et al. 2014. Accuracy comparison between implicit and explicit single-diode models of photovoltaic cells and modules. Acta Phys. Sin 63(17): 178401-1-10.

[4] R Chenni et al. 2007. A detailed modeling method for photovoltaic cells[J]. Energy 32(9): 1724-1730.

[5] W Herrmann et al. 1996. Current-voltage translation procedure for PV generators in German 1000 roofs-programme, EUROSUN conference 1-7.

[6] Chiu Chiansong et al. 2010. T-S Fuzzy Maximum Power Point Tracking Control of Solar Power Generation Systems. Energy Conversion, IEEE Transactions on 25(4):1123-1132.

[7] Zhang Chao et al. 2009. MPPT with asymmetric fuzzy control for photovoltaic system. Industrial Electronics and Applications 2180-2183. 